Forthcoming in Legal Theory (2013).

\title{
FIRST ACTS, LAST ACTS, AND ABANDONMENT ${ }^{1}$
}

David 0. Brink

University of California, San Diego

Gideon Yaffe's Attempts is a rich and rewarding study of the metaphysics and jurisprudence of attempted crimes that defends a view about what attempts are, to which he appeals in explaining various aspects of the settled criminal law doctrine of attempts and in providing guidance and reform where the doctrine is not settled or questionable. ${ }^{2}$ The book focuses on three main issues: (1) what an attempt is, (2) what kind of evidence is required that an attempt has been made, and (3) what is a fair sentence for an attempt relative to the sentence for completion. Yaffe argues that to try or attempt something is to be committed via an intention to each component of a completed crime and to be guided by those commitments. A first act or bodily movement that is a means to completing the crime is necessary as evidence of such a guiding commitment. And while the sentence for completed crimes sets an upper limit on the sentence for the corresponding attempts, it is not unfair to punish attempts less than their completed counterparts. Along the way, Yaffe sheds light on a variety of puzzles about the jurisprudence of attempts. Though his project displays real theoretical elegance, bringing a few powerful and intuitive ideas from action theory to bear on the jurisprudence of attempts, the result is a very complex and dense argument, one that will repay careful study and re-study.

My focus is less on Yaffe's reconstruction and reform of criminal law doctrine concerning attempts and more on whether certain assumptions about attempts make good normative sense. In particular, I am interested in whether the distinctions Yaffe draws among different stages in the path from the formation of an intention, to the so-called first act, to possible points of abandonment, to the so-called last acts, and the moral differences, if any, between completions and attempts that share a so-called last act. I think there is reason to question some of Yaffe's normative claims about this path, but I don't pretend to have an alternative theory articulated with comparable systematicity and sophistication. I have the more modest aim to stir the intellectual pot that Yaffee put on the fire.

\section{ATTEMPTS}

Yaffe embraces the transfer principle, which connects criminal liability for completions and mere attempts.

If a particular form of conduct is legitimately criminalized, then the attempt to engage in that conduct is also legitimately criminalized [21].

${ }^{1}$ An earlier version of this material was presented at a symposium on Gideon Yaffe's book Attempts at the 2011 meetings of the Pacific Division of the American Philosophical Association. Michael Bratman and Michael Moore were co-symposiasts. I would like to thank the Michaels and Gideon for useful discussion.

${ }^{2}$ Gideon Yaffe, Attempts (Oxford: Clarendon Press, 2010). Parenthetical references in the text will be to pages in this book. 
To attempt or try to do something is to have an intention-based commitment and to be guided by such a commitment. To intend to do something requires an action plan that is subject to norms of consistency, means-ends coherence, and agglomerativity (65), and that plan must guide the agent's action (73). But intention is insufficient for attempt (91). The intention must guide the agent's conduct.

There is guidance by a commitment iff the intention that constitutes the commitment non-deviantly causes an event as part of motivating an action that the agent believes will fulfill, or believes will serve as a means of fulfilling, the intention [92].

Motivational influence is to be cashed out in counterfactual terms. In particular, to be motivated by one's guiding commitments, the following completion counterfactual must be true: If the agent had the ability and opportunity to do $\mathrm{C}$, did not fall prey to execution failure, and did not change her mind, then she would do C (94). ${ }^{3}$

To give an account of criminal attempt, this guiding commitment conception of trying must involve a guiding intention directed toward each element of the crime -- act, results, attendant circumstances, and mens rea.

\section{FIRST ACTS AND BEYOND}

For a guiding commitment to lead to a completion or last act attempt will require the agent to engage in actions that are bodily movements pursuant to her plan. So-called last acts are completed attempts, including all the conduct that the agent needs to complete the crime. What separates last act attempts from completions is resultant luck. The last act of my attempted murder might consist in pointing my gun at you and pulling the trigger. While this last act will often lead to a completed crime of murder, it will not if, unbeknownst to me, you turn out to be wearing a bullet-proof vest. But attempts are not restricted to last acts, because one may well have gotten quite far in planning criminal activity and executing one's plan, short of the last act. It is sometimes said that attempts occur when the agent moves from a purely preparatory phase of planning to perpetration or implementation of the plan. ${ }^{4}$ The Model Penal Code says that the agent must take a "substantial step" toward the commission of a crime. ${ }^{5}$ When exactly, within a plan, does the attempt occur? Yaffe recognizes an attempt whenever there is guidance by criminal intent, and the completion counterfactual will often be true of agents as they are guided by these intentions, well before they reach the last act.

In fact, it seems that one can be guided by criminal intention prior to performing any bodily movements in public space. In particular, one can engage in elaborate goal-directed

${ }^{3}$ Execution failure, as Yaffe explains, involves the failure to execute something one is competent to do, as in Austin's famous illustration of failing to execute a short golf putt that one is able to make (94). See J.L. Austin, "Ifs and Cans" reprinted in J.L. Austin, Philosophical Papers (Oxford: Clarendon Press, 1979), p. 218n.

4See, e.g., Joshua Dressler, Understanding Criminal Law, 5th ed. (Boston: LexisNexis, 2009), p. 380.

${ }^{5}$ American Law Institute, Model Penal Code $\$ 5.01(1)(\mathrm{c})$. 
planning in one's head. These are genuine attempts. But if we applied the Transfer Principle to them, we would be recognizing and punishing "pure thought" crimes, which many jurists and Yaffe find abhorrent. Yaffe's solution to this problem, developed in Chapter 8, is to insist that we need evidence of guiding criminal intent and that the only plausible evidence of such intent is an act that is a bodily movement in public space in furtherance of the agent's plan. Though Yaffe recognizes that there are purely mental acts conforming to the guiding commitment view, he claims that only public acts can satisfy the evidential test necessary for criminalizing attempts.

But the evidential requirement does not rule out purely mental attempts, because we could have evidence of elaborate mental planning. Brain scans in the not-so distant future might be able to provide reliable evidence of such plans. There would be interesting evidentiary issues about the circumstances under which brain scans were constitutional and admissible. But one can imagine some such circumstances, and if the brain scans are sufficiently reliable, it's not clear why they would not provide evidence of purely mental planning. Short of that, we could imagine various scenarios in which agents provide reliable reports about their mental plans. Perhaps they describe their plans to others, which could then provide credible evidence of purely mental planning. Michael Bratman imagines someone engaged in elaborate mental planning of a crime who is also a candid and reliable blogger about his thoughts and actions, including his criminal plans. ${ }^{6}$ of course, some of these sources of evidence are themselves public acts, but they are not public acts in the service of or as means to the execution of the criminal plan, so they are not parts of the plan. But then they are evidence of a plan that is itself, so far, purely mental. It's not clear why there couldn't in principle be evidence of criminal attempts that are purely mental.

In light of the fact that one could have evidence about purely mental attempts, one might ask why the specter of thought crimes is so abhorrent. One should not conflate criminalizing purely mental attempts with the punishment of "mere thoughts". Presumably, thought police would surveil the citizenry for bad thoughts, as well as bad actions, and would target inappropriate beliefs, desires, and fantasies. That would be worrisome for various sorts of reasons. But, of course, we need to distinguish between inappropriate thoughts, on the one hand, and criminal plans, on the other. Targeting attempts, even purely mental attempts, does not commit us to targeting all inappropriate mental states. If the Transfer Principle is right, why should the reach of the criminal law in regulating criminal attempts stop with a person's skin? Why should we care if the plan is being worked out in a person's head or on paper?

One might resist criminalizing purely mental attempts, not on the ground that they are not attempts or on the ground that we can't have evidence of them, but rather on the ground that, at least typically, they are too far removed from the last act to justify censure or sanction. Yaffe seems not to recognize distinctions between more and less complete attempts, and his test for guiding commitments, including the completion counterfactual, seems to yield all-or-nothing verdicts. A guiding commitment is sufficient for attempt, and there is a guiding commitment at any point in the plan provided the completion counterfactual is true, that is, the agent would complete the crime then if she had the ability and opportunity, did not suffer execution failure, and did not change her mind. This

${ }^{6}$ See Michael Bratman's contribution to this symposium. 
condition can be satisfied at the first, as well as the last act. And, I have argued, it can be satisfied during purely mental planning. This shows that there is an important sense in which Yaffe's view of guiding commitments is dispositional.

By contrast, we might entertain what seems to me a different view of plans and attempts -- one that is both historical and scalar. We might think of complete plans as extended decision trees with some early nodes that might be purely mental but that also have many subsequent nodes that are public actions. Such decision trees terminate in last acts. On this view, the completion of attempts can be thought of as a scalar phenomenon in which attempts are only complete at the last act but can be more or less complete at different nodes depending on the proximity of that node to the last act. The completeness of an attempt may depend not only on the number of nodes through which the agent has progressed and the number of nodes remaining until the last act but also on the importance of the nodes. ${ }^{7}$ An attempt might remain substantially incomplete even if a small number of steps in the plan remain before the last act if these are especially significant steps, and an attempt might be substantially complete even though several steps in the plan remain to be performed if these are especially inconsequential steps. It might be possible for purely mental planning to constitute a substantially completed attempt if all the planning has been done in advance mentally and only one or two steps of implementation remain. However, in the normal case, presumably, a purely mental plan occupies a small part of the decision tree and so involves a substantially incomplete attempt.

At least as a matter of ideal theory, censure and sanction should be proportionate to the degree to which the attempt is completed -- roughly speaking, the proximity to the last act. If so, then purely mental attempts are not in principle beyond the reach of censure and sanction, but it may nonetheless be true that typically they deserve significantly less censure and sanction than public acts further along the decision tree. Of course, there may be a variety of pragmatic reasons for adopting a more coarse-grained conception of attempts. At one coarse-grained extreme, one might recognize only bivalent verdicts about whether an attempt has been made. If we are to recognize attempts prior to last acts, we must set some threshold for progress through a decision tree as the test for whether an attempt has been made. Use of thresholds to determine the function from scalar input to binary output is always somewhat arbitrary, which is why binary verdicts in such situations involve pragmatic compromises that are part of non-ideal theory. While ideal theory would not claim that purely mental attempts are impossible, it's possible that nonideal theory would rule them out for pragmatic reasons.

I don't think that the guiding commitment view, as such, need deny these claims about the extended and scalar dimensions of attempts. One could analyze attempts in terms of guiding commitments and think that this involves a process that progresses toward completion. Yaffe's version of the guiding commitment view does not seem to recognize that attempts can be partial, because it just focuses on whether an attempt has occurred and says that there has been an attempt any time there has been guidance by an

${ }^{7}$ There is disagreement within the common law and between some strands in the common law and the Model Penal Code about whether to measure completeness by the distance traveled from the first act or the distance remaining to the last act. Cf. Dressler, Understanding Criminal Law, pp. 397-402 and Model Penal Code, Comment to §5.01, at 329. However, it's not clear why these two different perspectives can't converge on a result. 
intention to commit the offense, where guidance is determined by whether the completion counterfactual is true. It's these aspects of the guiding commitment view that obscure the temporally extended and scalar dimensions of attempts. This alternative conception of attempts as historical and scalar is worth exploring and will be important, I think, for making sense of abandoned attempts. ${ }^{8}$

\section{ABANDONMENT}

Abandonment occurs when an agent aborts a criminal plan before its completion. Abandonment is only exculpatory when undertaken for the right reasons, involving a genuine change of heart, not simply because of fear of apprehension or desire to await a better opportunity for wrongdoing. ${ }^{9}$ The Model Penal Code $§ 5.02(4)$ and 26 jurisdictions treat genuine abandonment as an affirmative defense that justifies acquittal. Yaffe illustrates abandonment with the case, discussed by Joshua Dressler, in which a Palestinian suicide-bomber aborts her plan as she approaches the site where the detonation was to take place when she sees the innocent children she would be killing and fully realizes the atrocity she had been planning (288). ${ }^{10}$ One should note that this case involves wholesale abandonment, for the right reasons, but at a fairly late stage in the plan. Abandonment occurs near completion, though important steps remain to be taken. One could imagine other, even clearer, cases in which abandonment occurs earlier.

Accepting abandonment as a defense creates a prima facie puzzle for Yaffe's conception of attempts. Recall that he thinks that there is an attempt provided the agent has been guided in a criminal commitment and the completion counterfactual is true. These conditions can be satisfied by a first act, perhaps even a purely mental first act. But it seems quite possible for these agents to change their mind subsequently and prior to the last act, abandoning their criminal plans, as the Palestinian suicide-bomber does. But if abandonment is an affirmative defense, how can the prior plan qualify as a criminal attempt?

Yaffe in effect "solves" the problem by rejecting the idea that abandonment can be an affirmative defense. The agent who abandons her plan to be a suicide-bomber is guilty of criminal attempt, Yaffe claims, by virtue of her prior plans and the way they guided her prior actions. But, according to Yaffe, her abandonment, though it is not a defense, can nonetheless serve as a mitigating factor at sentencing, much as remorse can serve as a mitigating factor at sentencing for a completed crime (291-301).

This is a solution to the puzzle that gives Yaffe a consistent position. But I am not sure that it's a plausible view. Mitigation is an unsatisfactory response to genuine abandonment in part because mitigation is typically discretionary and partial. But it is also an inappropriate remedy as mitigation occurs at the sentencing phase of a criminal trial, after a finding of culpable wrongdoing at the guilt phase of the trial. But the agent who abandons her criminal plans at a very early stage, say just after the first act, and does so for

8If the extended and scalar dimensions of attempts can be squared with Yaffe's version of the guiding commitment view, then the discussion here could be read as a recommendation to acknowledge these dimensions more clearly and explore their significance more fully. ${ }^{9}$ See Dressler, Understanding Criminal Law, pp. 411-12 and Model Penal Code \$5.02. ${ }^{10}$ Joshua Dressler, Cases and Materials on Criminal Law, 4th ed. (St. Paul: West, 2003), p. 800. 
the right reasons, seems not to be guilty of culpable wrongdoing, and so partial mitigation at the sentencing phase of a trial seems not the right response.

This brings out the way in which possibilities of abandonment are linked conceptually with onset of attempt. The earlier we set the threshold for genuine attempt, the fewer are the possibilities for abandonment. Conversely, the greater the possibilities for abandonment, the closer the threshold for genuine attempt must be to the last act. Because Yaffe's account of guiding commitment implies a very early threshold for attempt, he is committed to denying any significant role to abandonment. By contrast, if one adopts the historical and scalar conception of plans and attempts, discussed in the previous section, this allows one to say that attempts are only complete at the last act and are incomplete, to various degrees, prior to that. This allows some room for abandonment quite late in the plan, though the degree of abandonment that is possible presumably shrinks in proportion to the degree to which the plan gets completed. Insofar as abandonment is an affirmative defense, it is not clear whether it is best regarded as a justification or an excuse. But, in any case, at least at the level of ideal theory, the defense that abandonment provides should be inversely proportional to the completion of the attempt.

This view of abandonment rests on my historical and scalar conception of plans and attempts. I have to concede that this conception is somewhat metaphorical. Indeed, my metaphor has something in common with what Yaffe calls the "geographical" metaphor that thinks of attempts as involving progress along a route from intention formation to the completion of the attempt, which he associates with James Fitzjames Stephen (257-73). ${ }^{11}$ Yaffe ends up accepting this metaphor, when it is interpreted in light of the completion counterfactual. But I think that it is the completion counterfactual that is inconsistent with the main point of the metaphor to recognize that plans and attempts are extended things through which agents progress and that determine how complete an agent's attempt is at any given point. In any case, it would be interesting to explore this alternative conception of the geographical metaphor more fully to see if we can't understand the right sort of abandonment as an affirmative defense.

\section{LAST ACTS AND MORAL LUCK}

As an agent makes progress through a plan or guiding commitment toward its completion, she eventually reaches the last act that is common to completed crimes and completed attempts that are not successful for purely fortuitous reasons. For instance, agent A may act on his plan to kill someone, pulling the trigger and killing his victim, while agent B may act on her plan to kill someone, pulling the trigger and failing to kill her victim only because, unbeknownst to her, her victim was wearing a bulletproof vest. A and B both perform the same last act, but the results are, through no fault or credit of their own, quite different. Should we punish A more severely for his completed crime than we punish B for her completed attempt? This is the familiar issue of moral luck. Moral luck would imply that it is permissible, indeed, perhaps obligatory, to punish completed crimes and unsuccessful last acts differently, because of their different outcomes. By contrast, luck skepticism would insist that the two cases be treated the same, because the agents were equally culpable for what was within their control. Philosophical and jurisprudential

11See James Fitzjames Stephen, A Digest of Criminal Law (London: Macmillan, 1883), §49. 
opinion on moral luck is divided. ${ }^{12}$ Criminal law doctrine is also divided, if somewhat less so: most common law jurisdictions embrace moral luck and differential punishment (the sanction for attempts is typically half the maximum sanction for the completed crime), but some jurisdictions follow the Model Penal Code by denying moral luck and insisting on equal punishment for successful and unsuccessful last acts. ${ }^{13}$

Yaffe treats the principal source of skepticism about moral luck as appealing to the apparent unfairness of punishing A and B differently when they perform the same last act (311). It can seem unfair to punish attempts and completions differently when they are equally culpable for their actions and when the differential outcomes they produce are outside their control.

In Solomonic fashion, Yaffe defends a mixed view about moral luck in the punishment of attempts. His mixed verdict depends on the distinction he draws between censure and sanction (31-33, 313-16). Typically, when the law criminalizes conduct, it both censures and provides sanctions for that conduct. But the two functions are conceptually distinct and, in fact, come apart in some situations (31-32). For instance, when particular agents have prosecutorial immunity from certain crimes, Yaffe claims, they can still perform prohibited acts, even if they are not subject to sanction. Similarly, he claims, an excuse, such as insanity, defeats the imposition of sanctions, but not of censure, because there is still wrongdoing, even if it is not culpable. By distinguishing between censure and sanction, Yaffe ends up with a mixed verdict on moral luck. He rejects moral luck when it comes to censure, but not when it comes to sanction or punishment (323).

Yaffe's mixed verdict on moral luck depends not only on the distinction between censure and sanction but also on a mixed theory of punishment according to which the appropriateness of censure and a range or window of possible sanctions are determined by backward-looking retributive considerations of desert but the precise magnitude of the sanction can be determined by forward-looking considerations of various kinds (316). This, he thinks, provides space for sanctioning crimes and completed attempts differently, even if we don't censure them differently.

The distinction between censure and sanction is interesting, as is its use to defend a mixed view about moral luck and attempts. But I am not yet fully persuaded, both because I am not sure about how to draw the distinction between censure and sanction, and

12The modern debate started with classic papers by Williams and Nagel. See Bernard Williams, "Moral Luck" reprinted in Bernard Williams, Moral Luck (London: Cambridge University Press, 1981) and Thomas Nagel, "Moral Luck" reprinted in Thomas Nagel, Mortal Questions (New York: Cambridge University Press, 1979). Also see Joel Feinberg, "Equal Punishment for Failed Attempts: Some Bad But Instructive Arguments Against It" Arizona Law Review 37 (1995): 119-21; Michael Moore, Placing Blame (Oxford: Clarendon Press, 1997), ch. 5; and Larry Alexander, Kimberly Ferzan, and Stephen Morse, Crime and Culpability (New York: Cambridge University Press, 2009), ch. 5. For a useful overview of the debate, see Dana Nelkin, "Moral Luck" Stanford Encyclopedia of Philosophy $<$ http://plato.stanford.edu/entries/moral-luck>.

${ }^{13}$ Cf. Dressler, Understanding the Criminal Law, pp. 381 and 418-19, and Model Penal Code $\S 5.05(1)$. The Model Penal Code makes an exception and provides differential sanction for first-degree felonies (murder, kidnapping, rape, and robbery), insisting that an attempt to commit a first-degree felony constitutes a second-degree felony. 
because I am not sure how that distinction allows us to sanction crimes and attempts differently if we must censure them the same.

It seems right that one can distinguish, at least conceptually, between the criminal law's prohibition or regulation of conduct, on the one hand, and its imposition of sanctions for noncompliance, on the other hand. In principle, you could regulate without imposing sanctions for noncompliance. This is one way of understanding the distinction between censure and sanction. Perhaps this gives us a good way of conceptualizing prosecutorial immunity: when an agent has immunity from prosecution, his otherwise criminal conduct is still censured, just not sanctioned. The alternative would be to say that when a class of agents has prosecutorial immunity that carves out an exception to the scope of the prohibition. I'm not sure what to say here, and immunity is something of a special case.

So we might turn to the case of excuse. Yaffe thinks that we justifiably censure someone with a full excuse, it's only sanctions that are not justified. But censure seems to imply blame. If so, censure is not appropriate where wrongdoing is excused. The criminal law, many believe, is predominantly retributive. ${ }^{14}$ Blame and punishment aim to track culpable or responsible wrongdoing. Wrongdoing and culpability are independent variables. Affirmative defenses, whose success justifies acquittal, deny either wrongdoing or culpability. Justifications, such as the necessity defense, deny wrongdoing, insisting that behavior that would otherwise be wrong is not in fact wrong in these circumstances. Excuses, such as the insanity defense, deny culpability or responsibility, claiming that the agent acted wrongly but was not responsible for the wrongdoing because not sufficiently normatively competent at the time. Blame presupposes responsibility, and so blame is inappropriate when an agent's actions are fully excused, because she is insane or otherwise insufficiently normatively competent. If censure is a form of blame, then censure is not justified where there is an excuse.

So I'm puzzled about how exactly to draw the distinction between censure and sanction and whether the distinction has a significant role to play in our understanding of the criminal law.

Moreover, this defense of moral luck is only as plausible as the mixed theory of punishment on which it is based. Yaffe does not argue for the view. A form of retributivism that claimed that the magnitude of punishment should be proportional to desert, where desert is the product of wrongdoing and culpability, would not leave any more room for differential punishment than for differential censure. But then this defense of moral luck fails unless there is a reason to prefer Yaffe's mixed theory to this kind of retributivism.

Moreover, I wonder if the defense of moral luck works even on Yaffe's own mixed conception of punishment. Even if we allow consequentialist or "contextual" considerations to help determine exactly how much punishment within a range of

${ }^{14}$ See, for example, Moore, Placing Blame and Alexander, Ferzan, and Morse, Crime and Culpability. Elsewhere, I have defended a view I call Predominant Retributivism, which claims that culpable wrongdoing is the desert basis of punishment -- determining whom we should punish, why we should punish them, and how much we should punish them - but allows that forward-looking consequential considerations (such as rehabilitation and deterrence) can play a role in answering the question how we should punish. See David 0. Brink, "Immaturity, Normative Competence, and Juvenile Transfer" Texas Law Review 82 (2004): 1555-85 and "Retributivism and Legal Moralism" Ratio Juris 25 (2012): 496-512. 
punishments -- set by desert -- to assign to different equally culpable offenses, I'm not sure why we would think that these consequentialist considerations favor punishing completions more than last act attempts. It's not obvious how goals of deterrence, whether specific or general, rehabilitation, expression of community norms, etc. favor punishing completions more than last act attempts.

These considerations leave me wondering if Yaffe can coherently deny censure-luck and embrace sanction-luck. His case for the mixed verdict depends on the distinction between censure and sanction, his mixed theory of punishment, and the claim that forward-looking rationales for fine-tuning punishment whose boundaries are set by desert favor punishing last act attempts less than completed crimes. I think each assumption in this argument requires fuller defense if Yaffe's mixed verdict on moral luck and attempts is to succeed. 